\title{
Fresh and some mechanical properties of sifcon containing silica fume
}

\author{
Shakir Salih ${ }^{1}$, Qais Frayyeh, ${ }^{1, *}$, and Manolia $\mathrm{Ali}^{2}$ \\ ${ }^{1}$ Building and Construction Engineering. Department, University of Technology, Baghdad, Iraq \\ ${ }^{2}$ Material Engineering Department, Collage of Engineering, Al-Mustansiriya University, Baghdad, Iraq
}

\begin{abstract}
Slurry infiltrated fiber concrete (SIFCON) is one of the recently developed construction material. SIFCON could be considered as a special type of fiber concrete with high fiber content. The matrix of SIFCON consists of flowing cement mortar or cement slurry. SIFCON has a very good potential for application in area where resistance to impact and high ductility are needed especially in designing the seismic retrofit, in the structures under impact and explosive effects and repair of structural reinforced concrete element. The main objective of this paper is to determine the effect of steel fiber content and silica fume (SF) cement replacement on the mechanical properties of SIFCON concrete. The percentage of SF replacement was $10 \%$ by weight of cement in SIFCON slurry, and three different volume fractions of hooked ended steel fiber $(6,8.5$, and 11$) \%$ were used. The tested properties of SIFCON were compressive strength and splitting tensile strength which were carried out on standard size of cubes and cylinders respectively at the age of 7 and 28 days. It was observed that the mechanical properties of SIFCON were affected in a positive manner by using silica fume as a partial replacement of cement and by adding steel fiber reinforcement in different percentages. The compressive and splitting tensile strength up to $83.7 \mathrm{MPa}$ and 17.3MPa, respectively were obtained at the age of 28 days.
\end{abstract}

\section{Introduction}

Slurry Infiltrated Fibrous Concrete (SIFCON) is relatively a new high performance and advanced material [1] that differs from ordinary Fiber Reinforced Concrete (FRC) in terms of fabrication and composition [2].Fiber content in FRC generally varies from (1 to 3) $\%$ by volume, while the fiber content of SIFCON can be anywhere from (4 to 20$) \%$ even though the current practice ranges from ( 4 to $12 \%$, and when using hooked ended steel fiber with length more than $30 \mathrm{~mm}$ the fiber content range between (4 to10)\%. SIFCON matrix has no coarse aggregates but a high cementitious content. It may contain fine or coarse sand and mineral admixture such as silica fume, fly ash and latex emulsions [3]. So, the matrix of SIFCON is either cement paste or flowing cement mortar as opposed to regular concrete used in FRC. Also, the production of SIFCON far different from FRC which is produced by adding the fiber to the wet or dry concrete mix. While SIFCON is produced by first sprinkling fibers into a mold until it is completely filled, then the fiber network of SIFCON is infiltrated by cement slurry $[2,4,5]$.

SIFCON is a unique construction material exhibiting new behavioral phenomenon, that of Fiber lock, the fibers are subjected to mechanical and frictional interlock, in addition to the bond with the matrix, which is believed to be responsible for its outstanding stressstrain properties. SIFCON also possesses high strength as well as large ductility and far excellent potential for structural applications when accidental loads are encountered during services [1].

Many researchers study the mechanical behavior of SIFCON produced with fly ash or ground granulated blast furnace slag replacement. Also, there is little information about SIFCON characteristic produced using silica fume as additional ingredient to cement paste or slurry

Sashidhar [6] examined the compressive strength characteristics of SIFCON produced with low tensile strength of steel fiber, ultimate tensile strength of 390 $\mathrm{MPa}$, using mineral admixtures like metakaoline and silica fume in the cement mortar. Fibers with 8 to $12 \%$ volume fraction and with aspect ratio of 40 to 60 were used. The study reported an $88 \%$ increase in compressive strength for SIFCON when compared to conventional concrete. It is further reported that the use of metakaoline and silica fume in the matrix cause increase of (11 to 14$) \%$ in the compressive strength of SIFCON.

Kim and Choi[7] studied the mechanical properties of SIFCON using hooked -end steel fiber with volume friction varying from $4 \%$ to $10 \%$. The addition of silica

*e-mail: jwd_ks@yahoo.com 
fume was $10 \%$ by weight of cement, and superplastisizer of $0.5 \%$ to improve the workability of cement slurry .The water /cement ratio was kept constant as 0.4 .The test results show that the compressive strength of SIFCON was increased to about (1.59 to 2.68) times when compared with the cement paste, while the increase in tensile strength was about (2.51 to 8.77) times than that of the cement paste. They also observed that the ductility and toughness of SIFCON were increased with increasing the volume fraction of steel fiber.

The flowable slurry with rich cement is the binder in SIFCON products. Using high amount of cement not only affects the production cost, but also has negative effects on heat of hydration and may cause shrinkage problems, therefore, the incorporation of mineral admixtures as a partial replacement of cement seems to be a suitable solution to overcome these problems, furthermore, the use of mineral admixtures may have a positive effect on mechanical properties and durability of SIFCON products.

There is very limited information about the behavior of SIFCON containing silica fume as a replacement of cement .Therefore, the main aim of this research is to evaluate the effect of silica fume as a partial replacement ( $10 \%$ by weight of cement)and the effect of volume fraction of steel fiber ranging from (6 to $11 \%$ ) on fresh and mechanical properties of SIFCON.

\section{Experimental Work}

\subsection{Materials}

\subsubsection{Cement}

Ordinary Portland cement (type I) which is commercially known as (Krasta) was used in this research, its physical and chemical properties conformed to the Iraqi specification NO.5/1984[8].

\subsubsection{Fine aggregate}

River sand passing through $1.18 \mathrm{~mm}$ sieves, to ensure complete infiltration through steel fiber, was used as a fine aggregate. It conformed to the Iraqi specification NO.45/1984[9], zone (2). Its specific gravity, sulphate content and absorption are 2.6, $0.34 \%$, and $2 \%$, respectively.

\subsubsection{Water}

Ordinary tap water was used in this work for all mixing and curing of SIFCON specimens

\subsubsection{Silica fume (SF)}

Densified silica fume, which is commercially known as MEYCO/MS610 from BASF Company with fineness of $\left(21000 \mathrm{~m}^{2} / \mathrm{kg}\right)$, was used in this work as a partial replacement of cement. It conformed to the ASTM C1240-05[10]

\subsubsection{High range water reducer (HRWR)}

For the production of SIFCON high range water reducing admixture was needed to improve the workability (flowability) of the slurry, which should be liquefied enough to flow through the dense fiber bed without leaving honeycombs. In this work (Glenium 54) from BASF Company was used. It conformed to the ASTM C494 type F [11].

\subsubsection{Steel fiber}

Hooked end steel fiber with diameter of $0.7 \mathrm{~mm}$ and length of $35 \mathrm{~mm}$, giving aspect ratio of 50 and tensile strength of $1100 \mathrm{MPa}$ was used in this investigation .Fibers were randomly orientated in the matrix.

\subsection{Mix proportion}

The first step in this work was preparing many trial slurry mixes to find a suitable mix that has the desirable fresh properties satisfying the requirements of SIFCON slurry with respect to viscosity, fluidity and filling ability without segregation or pore pockets in the fiber network. While the second step was selected the minimum and maximum volume fraction of steel fiber to be used after the trial mixes of SIFCON. Two types of SIFCON matrix $\left(M_{1}\right.$ and $\left.M_{2}\right)$ were prepared with the same mix proportion (1:1) (cement: fine aggregate) by weight depending on literature review findings which show that the proportion of sand to cement is equal to 1 in most cases, and the addition of sand beyond cement to sand ratio of $(1: 1)$ decreases the required compressive strength. The cement content was $885 \mathrm{~kg} / \mathrm{m}^{3}$ and (water /binder) ratio was kept constant at 0.3 for the two mixes $\left(\mathrm{M}_{1}\right.$ and $\left.\mathrm{M}_{2}\right)$. The first SIFCON matrix $\left(\mathrm{M}_{1}\right)$, control mix, was obtained by using a superplastisizer which is (Glenium 54). While the second type of SIFCON matrix $\left(\mathrm{M}_{2}\right)$ was prepared from the control mix by a partial replacement by weight of cement with $10 \%$ of silica fume (SF). The details of the two SIFCON mixes are shown in Table (1)

Table 1. Mix proportion used for SIFCON slurries

\begin{tabular}{|c|c|c|c|c|c|c|}
\hline $\begin{array}{c}\text { Mix } \\
\text { Symbol }\end{array}$ & $\begin{array}{c}\mathbf{w} / \mathbf{b}^{*} \\
\text { ratio }\end{array}$ & $\begin{array}{c}\text { Cement } \\
\mathbf{k g} / \mathbf{m}^{\mathbf{3}}\end{array}$ & $\begin{array}{c}\text { Sand } \\
\mathbf{k g} / \mathbf{m}^{\mathbf{3}}\end{array}$ & $\begin{array}{c}\mathbf{S F} \\
\mathbf{( 1 0 \%} \\
\mathbf{r e p . )} \\
\mathbf{k g} / \mathbf{m}^{3}\end{array}$ & $\begin{array}{c}\mathbf{W a t e r} \\
\mathbf{L} / \mathbf{m}^{3}\end{array}$ & $\begin{array}{c}\text { SP** } \\
\mathbf{\%} \text { by } \\
\mathbf{w t . ~ o f} \\
\text { cement }\end{array}$ \\
\hline$M_{1}$ & 0.3 & 885 & 885 & 0.0 & 265.5 & 1.2 \\
\hline$M_{2}$ & 0.3 & 796.5 & 885 & 88.5 & 265.5 & 2.4 \\
\hline
\end{tabular}

$*_{\mathrm{w}} / \mathrm{b}=$ water $/($ cement + silica fume $)$

**SP dosage was regulate to obtain similar flow diameter and viscosity (without bleeding and segregation)

Each mix was prepared with three volume fractions $(6 \%, 8.5 \%$ and $11 \%)$ of steel fiber. The volume fraction 
of $6 \%$ was a minimum practical limit that could fill the mold without using vibration while $11 \%$ volume fraction was the maximum practical limit that fills the mold with intense vibration to obtain complete penetration of the slurry into the fiber network. Volume fraction of $8.5 \%$ was selected as an intermediate value which required only light vibration

\subsection{Test of fresh SIFCON}

Testing of SIFCON in its fresh state is of serious importance for the production of SIFCON. Its matrix must be liquid enough and have sufficient fineness to flow through the dense fiber bed. The mini slump flow and $\mathrm{V}$-funnel test, according to EFNARC [12], were used to determine the flowability, filling ability and viscosity of the slurry. The mini flow test represents the flowability, segregation resistance and uniformity of the slurry. Base diameter, top diameter, and height of mini slump flow test apparatus used are 100, 70 and $60 \mathrm{~mm}$, respectively. A value between (240-260) $\mathrm{mm}$ spread diameters is required for SIFCON mortar. The other test to assess the viscosity of the slurry was V-funnel test, a flow time between (7-11) seconds is considered appropriate [12]. The details of these two tests could be found in many references $[12,13,14]$. Results of the fresh properties of SIFCON mixes are given in Table (2) and shown in Fig. (1)

Table 2. Fresh properties of SIFCON mix

\begin{tabular}{|c|c|c|c|}
\hline Mix Symbol & $\begin{array}{c}\text { Mini slump } \\
\text { flow (mm) }\end{array}$ & V-funnel (s) & $\begin{array}{c}\text { SP. \% by wt. } \\
\text { of cement }\end{array}$ \\
\hline$M_{l}$ & 258 & 8 & 1.2 \\
\hline$M_{2}$ & 257 & 9.5 & 2.4 \\
\hline
\end{tabular}

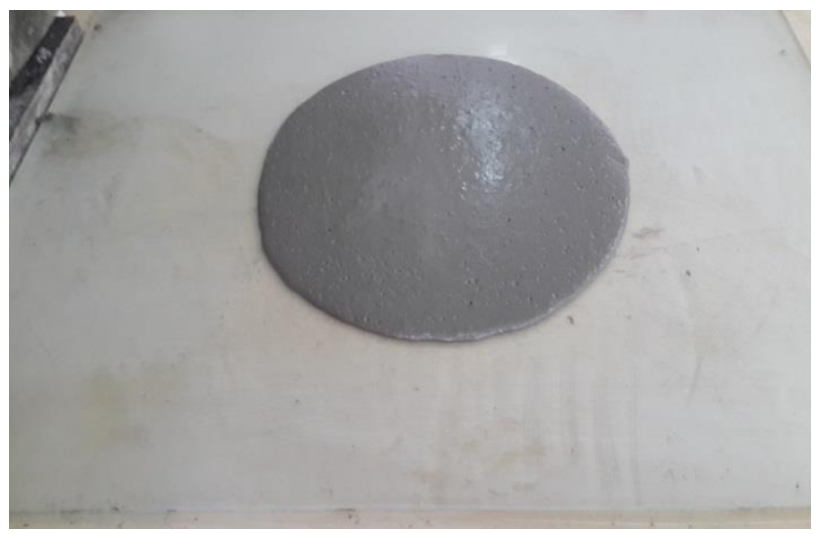

Fig.1. mini slump flow test for SIFCON slurry

\subsection{Preparing, casting, and curing of the test specimens}

The first step in preparing test specimens is placing steel fibers into the molds, and then they were infiltrated with the cement slurry which must be flowable and liquid enough to infiltrate thoroughly the dense matrix in the fiber -filled form.

In this study, casting of the two- layer technique was used for incorporating fiber in the mortar slurry, which proved effective during the casting of SIFCON specimens and found to be easier in actual practice than the single layer technique especially in case of high content of steel fiber

This technique involved initial placing of the fibers in the mold only up to the half depth, followed by infiltration of the slurry up to this level. Then the contents in the mold were vibrated. The process was repeated until the entire mold was filled with the required fiber content. No vibration was required with volume faction(Vf)of $6 \%$, while alight vibration for(6$10)$ sec by table vibrator was applied in case of $\mathrm{Vf}$ of $8.5 \%$ and intense vibration for(15-20)second in case of the maximum $\mathrm{Vf}(11 \%)$ to ensure that SIFCON slurry will penetrate completely into the fiber pack, as shown in Fig.(2).

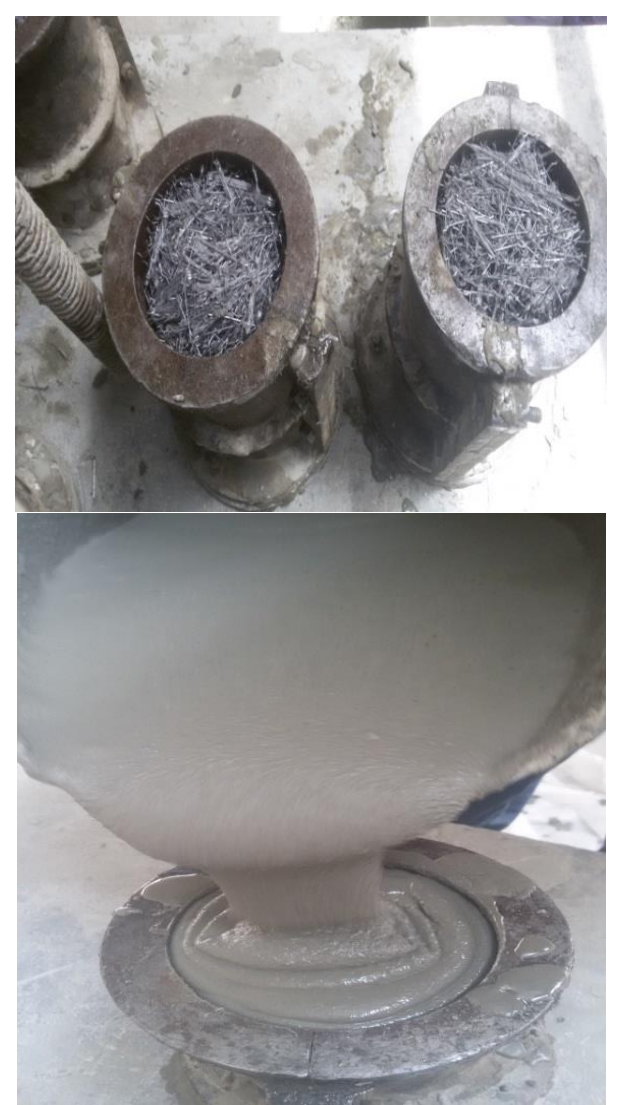

Fig.2. preparing and casting of SIFCON specimens 
The weight of steel fiber to be used in each mold depends on the dimensions of the mold, density and the volume fraction of the steel fiber used. After a bout 24 hours from casting time, the specimens were demolded, marked and immersed in tap water tank to be cured for 7 and 28 days.

\subsection{Testing of hardened SIFCON specimens}

\subsubsection{Compressive strength}

This test was conducted in accordance to B.S.1881: Part 116:1989[15] by using $100 \mathrm{~mm}$ cube. The compressive strength value of each mix represents the average of three specimens. They were tested at 7 and 28 days of water curing.

\subsubsection{Splitting tensile strength}

This test was carried out according to ASTMC496 04 [16] by using $(100 * 200 \mathrm{~mm})$ concrete cylinder. The specimens were tested at 7 and 28 days of water curing. The average of three specimens was used for each variable in this test.

\section{RESULTS AND DISCUSSION}

\subsection{Fresh properties of SIFCON}

Table (2) shows the results of mini slump flow and Vfunnel test that satisfied the criteria of appropriate flowability, adequate viscosity and filling ability for the two slurry mixes $\left(\mathrm{M}_{1}\right.$ and $\left.\mathrm{M}_{2}\right)$. It can be seen from the results of the reference mixture $\left(\mathrm{M}_{1}\right)$ that the addition of HRWR is very necessary to obtain a mixture with low $\mathrm{w} / \mathrm{c}$ ratio and in the same time satisfying the homogeneity and the other mentioned requirement.

The method followed to find the superplastisizer(SP) amount needed for $\mathrm{M}_{1}$ is by checking first the slump flow with different amount of SP until reaching the aimed value of $(240-260) \mathrm{mm}$, then checking the two other requirement by $\mathrm{V}$-funnel test. This is because the slump flow test is the simplest and the fastest one.

The great or positive effect of SP on fluidity and cohesiveness of cement slurry was because the polycarboxylate superplasticizer absorbs onto and disperses the cement particles; thus improving workability and reducing friction, and if the particles tend to flocculate then the multi-ion polymer interferes. These particles remain frictionless, so maintaining the dispersing effect for longer time after mixing [13].

The resulted feature of using silica fume (SF), as cement partial replacement, to reference mix $\left(\mathrm{M}_{1}\right)$ is shown in Table (2) as mix $\left(\mathrm{M}_{2}\right)$. It was noticed that this replacement caused a decrease of workability making the mix cohesive and sticky and to obtain similar viscosity and fluidity, the SP dosage of mixture has to be increased. Insufficient fluidity or viscosity was observed for lower SP dosage than the values given in Table (2). On the other hand, greater dosage caused bleeding and segregation behavior of mixtures. The lower workability and stickiness of the mixtures by SF replacement is a result of its very large surface area. The superplasticizer when mixed in concrete are absorbed by cement and silica fume particles, make them mutually repulsive as a result of anionic nature of superplasticizer, which causes the cement and silica fume particles to become negatively charged $[13,17]$

It can be seen from the results that SF incorporation reduces the spread diameter of mini slump and increases the $\mathrm{V}$-funnel time. In other words SF replacement causes relatively high viscosity. This can be attributed to increased cohesiveness with SF. Sonebi et al. [18] mentioned that the increased dosage of SF reduced the spread diameter of the mini slump and volume of penetrated slurry into the fiber mass.

\subsection{Hardened properties of SIFCON}

\subsubsection{Compressive strength}

The compressive strength test results for SIFCON cubes (100) mm cured at 7 and 28 days for two different types of mortar $\left(\mathrm{M}_{1}\right.$ and $\left.\mathrm{M}_{2}\right)$ with different volume fraction of steel fibers $(6 \%, 8.5 \%$ and $11 \%)$ are presented in Table(3) and plotted in Fig. (3), Fig. (4), Fig. (5) and Fig. (6).The results show that the compressive strength increases with the increase of steel fiber volume fraction for both the two groups (Group 1 and Group 2).

Table 3. Compressive strength of SIFCON mixes

\begin{tabular}{|c|c|c|c|}
\hline \multirow{2}{*}{$\begin{array}{c}\text { Group } \\
\text { No. }\end{array}$} & \multirow{2}{*}{ Mix symbol } & \multicolumn{2}{|c|}{ Compressive strength (MPa) } \\
\cline { 3 - 4 } & & $\mathbf{7}$ days & 28 days \\
\hline \multirow{3}{*}{1} & $\mathrm{M}_{1} \mathrm{~F}-6$ & 63 & 70.7 \\
\cline { 2 - 4 } & $\mathrm{M}_{1} \mathrm{~F}-8.5$ & 66.3 & 74.8 \\
\cline { 2 - 4 } & $\mathrm{M}_{1} \mathrm{~F}-11$ & 70.6 & 76.5 \\
\hline \multirow{3}{*}{2} & $\mathrm{M}_{2} \mathrm{~F}-6$ & 69.5 & 78.5 \\
\cline { 2 - 4 } & $\mathrm{M}_{2} \mathrm{~F}-8.5$ & 71.4 & 81 \\
\cline { 2 - 4 } & $\mathrm{M}_{2} \mathrm{~F}-11$ & 74.7 & 83.7 \\
\hline
\end{tabular}

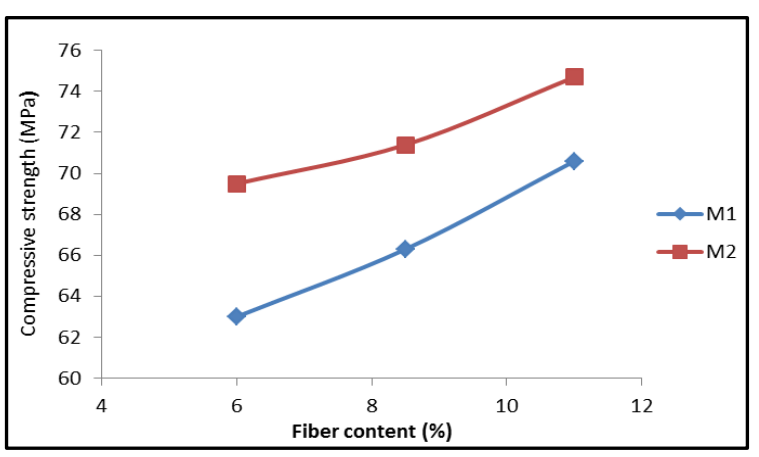

Fig.3.The effect of steel fiber content on the compressive strength for all SIFCON mixes at age of 7 days 


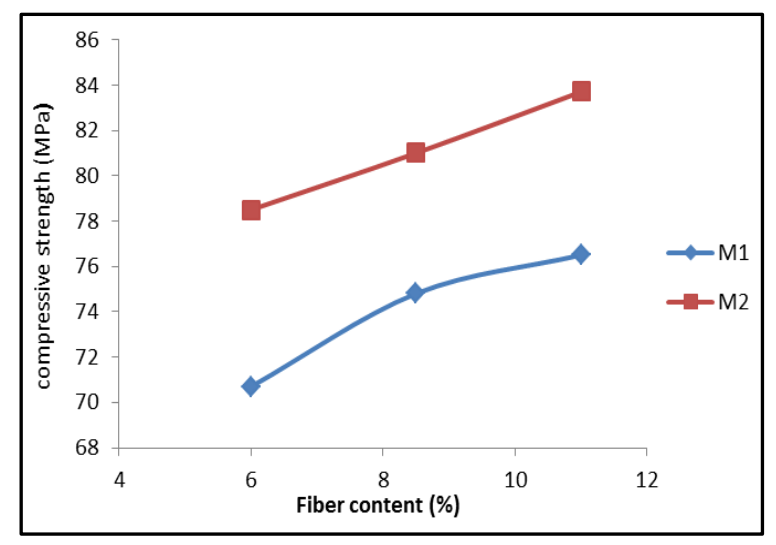

Fig.4. The effect of steel fiber content on the compressive strength for all SIFCON mixes at age of 28 days

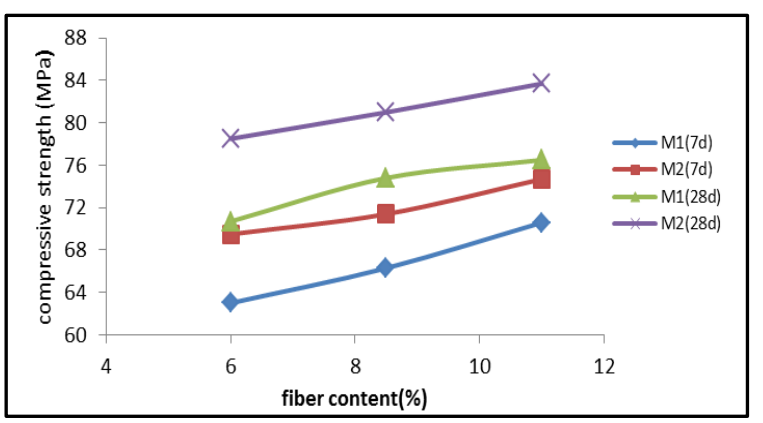

Fig.5. The effect of steel fiber content on the compressive strength for all SIFCON mixes at age of (7 and 28) days

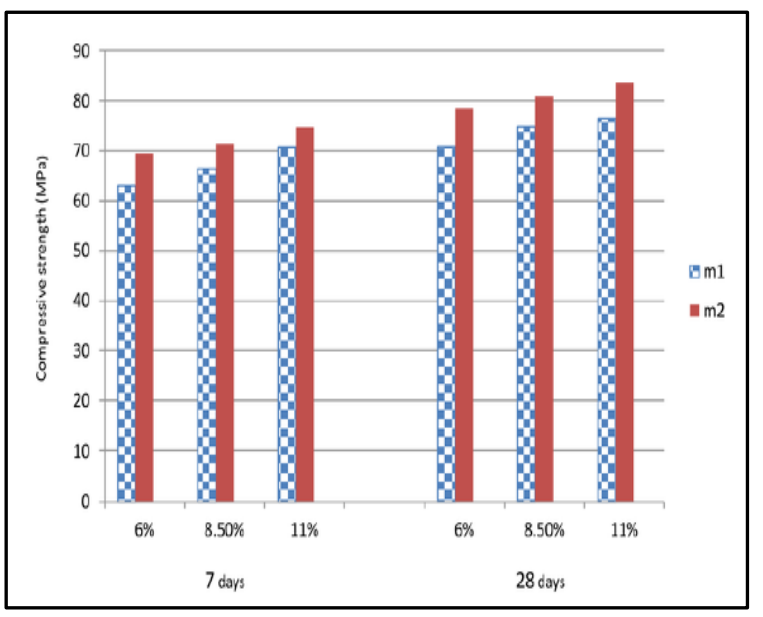

Fig.6. Compressive strength development with time for SIFCON mixes with different fiber content

For example, in Group (1), the increase in fiber content from $6 \%$ to $(8.5 \%$ and $11 \%)$ leads to increase in compressive strength of SIFCON mixes $\left(\mathrm{M}_{1} \mathrm{~F}-8.5\right.$ and $\left.\mathrm{M}_{1} \mathrm{~F}-11\right)$ to (5.2 and $12 \%$ ) at age of 7 days , and (5.8 and $8.2 \%$ ) at age of 28 days, respectively compared with $\mathrm{M}_{1} \mathrm{~F}-6$.This increase in compressive strength is due to the higher gained bond between fibers/ matrix interfaces by increasing fiber volume fraction up to $11 \%$.These findings are agreed with other researchers [19] and [20]. The results also show that all SIFCON mixes in Group 2 have a slight increase in the compressive strength due to the incorporation of silica fume (as a partial replacement by weight of cement), which causes an increase by about $(10.3 \%, 7.7 \%, 5.8 \%)$ for 7 days as well as $(11 \%, 8.2 \%$, $9.4 \%$ ) at the age of 28 days for $\mathrm{M}_{2} \mathrm{~F}-6, \mathrm{M}_{2} \mathrm{~F}-8.5$ and $\mathrm{M}_{2} \mathrm{~F}-11$ mixes in Group2 compared with their counterpart mixes in Group 1,as shown in Fig.(5) and Fig.(6).

The effect of SF on improving the compressive strength of SIFCON mixes is due to the high surface area of SF which fills in the spaces between cement grains. This phenomenon is referred to as (particle packing). Also SF accelerates the hydration of cement by providing nucleation sites where the products of cement hydration can more readily precipitate from solution result in more densified microstructure and also improve the cohesive force between fiber and matrix. SF is a very reactive pozzolana material which reacts with calcium hydroxide to form additional binder material called calcium silicate hydrate which is similar to the calcium silicate hydrate from Portland cement [13]

\subsubsection{Splitting tensile strength}

The tensile strength investigations of SIFCON mixes with two different types of mortar $\left(\mathrm{M}_{1}\right.$ and $\left.\mathrm{M}_{2}\right)$ and different volume fractions of steel fiber $(6,8.5$ and $11 \%)$ were carried out at the ages of 7 , and 28 days. The results are presented in Table (4) and plotted in Fig. (7), Fig. (8) and Fig. (9).

Table 4. Splitting tensile strength results for SIFCON mixes

\begin{tabular}{|c|c|c|c|}
\hline \multirow{2}{*}{$\begin{array}{c}\text { Group } \\
\text { No. }\end{array}$} & \multirow{2}{*}{ Mix symbol } & \multicolumn{2}{|c|}{$\begin{array}{c}\text { Splitting tensile strength } \\
\text { (MPa) }\end{array}$} \\
\cline { 3 - 4 } & & $\mathbf{7 ~ d a y s}$ & $\mathbf{2 8}$ days \\
\hline \multirow{3}{*}{1} & $\mathrm{M}_{1} \mathrm{~F}-6$ & 9.15 & 11.2 \\
\cline { 2 - 4 } & $\mathrm{M}_{1} \mathrm{~F}-8.5$ & 11.3 & 12.8 \\
\cline { 2 - 4 } & $\mathrm{M}_{1} \mathrm{~F}-11$ & 13.2 & 14.6 \\
\hline \multirow{3}{*}{2} & $\mathrm{M}_{2} \mathrm{~F}-6$ & 11.1 & 12.9 \\
\cline { 2 - 4 } & $\mathrm{M}_{2} \mathrm{~F}-8.5$ & 14.4 & 16.2 \\
\cline { 2 - 4 } & $\mathrm{M}_{2} \mathrm{~F}-11$ & 16.1 & 17.3 \\
\hline
\end{tabular}

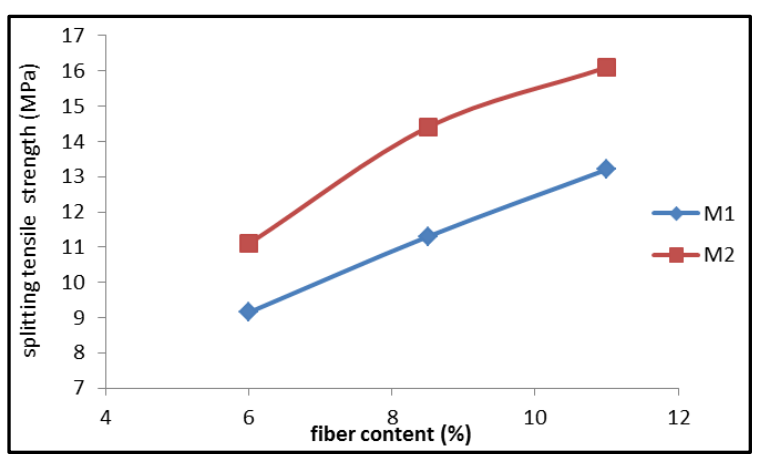

Fig.7.The effect of steel fiber content on the splitting tensile strength for all SIFCON mixes at age of 7 days 


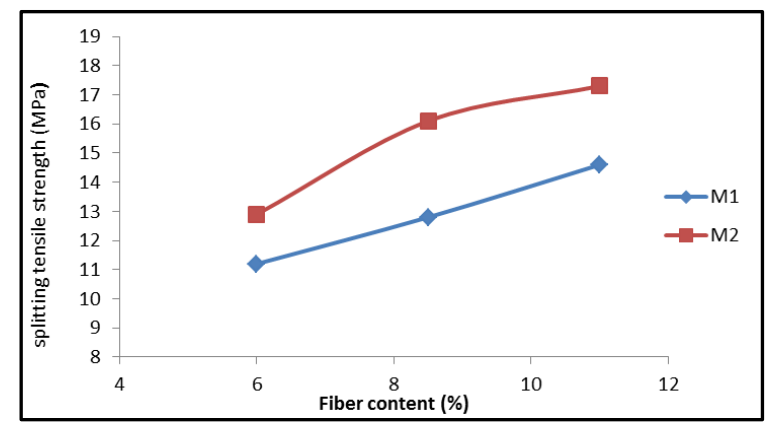

Fig.8. The effect of steel fiber content on the splitting tensile strength for all SIFCON mixes at age of 28 days

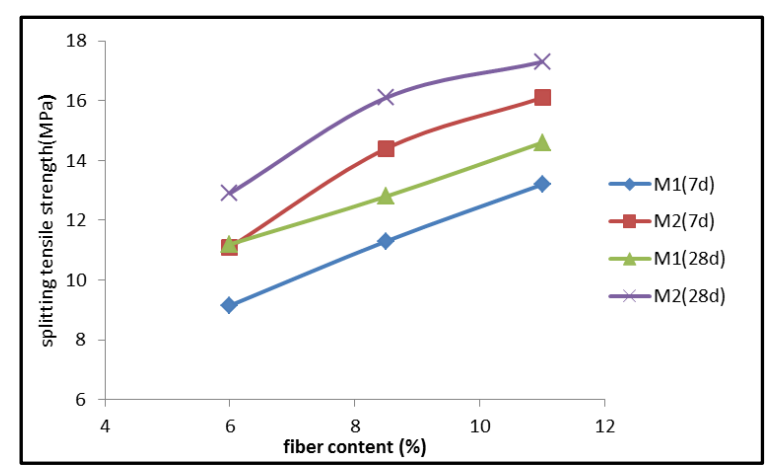

Fig.9.The effect of steel fiber content on the splitting tensile strength for all SIFCON mixes at age of (7 and 28 days)

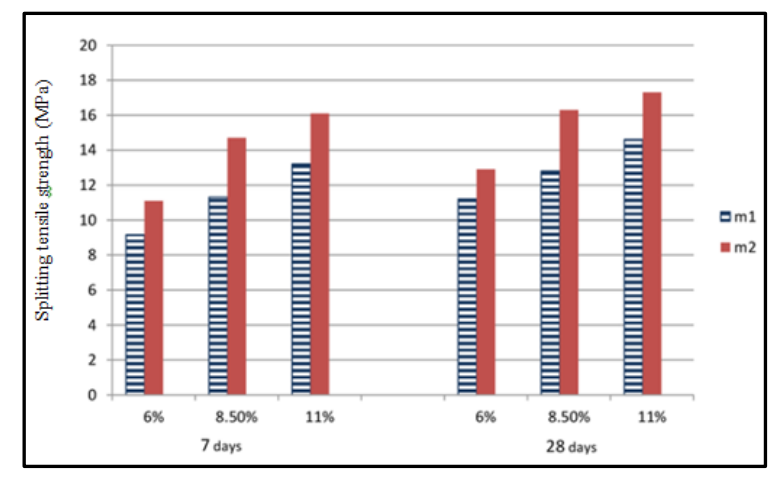

Fig.10. Splitting tensile strength development with time for SIFCON mixes

The results show that splitting tensile strength increases with the increase in volume friction of steel fiber for both the Groups (Group 1 and Group 2).Also the effect of steel fiber content on increasing the tensile strength was more than its effect on compressive strength

As shown in Group (1), the increase in fiber content from $6 \%$ to $(8.5 \%$ and $11 \%)$ increases the splitting tensile strength of SIFCON mixes $\left(\mathrm{M}_{1} \mathrm{~F}-8.5\right.$ and $\left.\mathrm{M}_{1} \mathrm{~F}-11\right)$ to $(23.5$ and $44.3 \%)$ for the age of 7 days , and (14.3 and $30.4 \%$ ) for the age of 28 days ,respectively compared with $\mathrm{M}_{1} \mathrm{~F}-6$.And in Group (2) the increase in splitting tensile strength of SIFCON mixes $\left(\mathrm{M}_{2} \mathrm{~F}-8.5\right.$ and $\left.\mathrm{M}_{2} \mathrm{~F}-11\right)$ to $(29.7$ and $45 \%)$ at age of 7 days, and $(25.5 \%$ and $34.1 \%$ ) at age of 28 days, respectively compared with $\mathrm{M}_{2} \mathrm{~F}-6$.The reason behind this behavior is due to arresting the macrocracks as well as microcracks by effect of steel fiber, also using hooked end SF leads to an improved bond which in turn leads to an improved mechanical properties.

The results show that Group 2 SIFCON mixes have an improved tensile strength due to the incorporation of silica fume (SF) that results in an increase by about $(21.3 \%, 27.4 \%$, and $22 \%)$ for 7 days as well as $(15.2 \%$, $26.5 \%$, and $18.5 \%)$ at the age of 28 days for $\left(\mathrm{M}_{2} \mathrm{~F}-6\right.$, $\mathrm{M}_{2} \mathrm{~F}-8.5$, and $\mathrm{M}_{2} \mathrm{~F}-11$ ) mixes in Group2 compared with SIFCON mixes in Group1, as shown in Fig(10). It was mentioned that the filler effect, pozzolanic effect and the enormous surface area enhance the bond between fiber and matrix interface in addition to the growth restricting for microcracks, this explains the improved mechanical properties in Group 2.

\section{Conclusions}

1-The test results show that SF replacement with cement caused increase in the viscosity of slurry (decreased the spread diameter of mini slump and increased the Vfunnel time), which can be controlled by using proper dosage of SP. Therefore, SIFCON slurry having proper filling ability and flow ability properties can be produced with SF replacement

2-The mechanical properties of SIFCON (compressive strength and splitting tensile strength) were increased with increase in volume fraction of steel fibers. The increase in volume fraction of steel fibers from $(6 \%$ to $11 \%$ ) will increase the compressive and splitting tensile strength of SIFCON mixes $\left(\mathrm{M}_{1} \mathrm{~F}-11\right)$ to $12 \%$ and $44.3 \%$, respectively at the age of 7 days.

3- The use of silica fume (as a partial replacement by weight of cement) in the matrix resulted in an increase in the mechanical properties of SIFCON. The increases in compressive and splitting tensile strength were about $9.4 \%$ and $18.5 \%$, respectively at age of 28 days for $\mathrm{M}_{2} \mathrm{~F}-11$ mix.

\section{References}

[1] D. Shanthini , E.K. Mohanraj, International Journal of Science and Engineering Research (IJ0SER), 3, Issue $10,(.2015)$.

[2] D.R Lankard, Concrete International,.6, No.12, pp.44-47,(1984).

[3] R. Giridhar ,P. Rama , M. Rao, International Journal for Technological Research in Engineering , 2, Issue 7, (2015).

[4] D. R. Lankard. , J.K.Newell, SP-81, Fiber Reinforce Concrete-International Symposium, American Concrete Institute, Detroit, Mich, pp. 287-306,(1984). 
[5] M. Sonebi, L. Svermova , J.M. Bartos., ACI material journal ,pp.136-145,( 2004).

[6] C. Sashidhar, Ph.D Thesis, Jawaharlal Nehru Technology University, Hyderabad, (2005).

[7] S. kim , J.choi, journal of the Korea concrete institute, 18, No.5, pp703-708, ( 2006).

[8] Iraq Standard Specification (IQS) No.5,"Portland cement", Baghdad, 8p ,( 1984).

[9] Iraq Standard Specification (IQS) No.45,"Natural sources of aggregate used in building and concrete", Baghdad, 13p,(1984) .

[10] ASTM C 1240 - 05, "Standard Specification for Silica Fume Used in Cementitious Mixtures", American Society for Testing and Material International, 04.02, (2005).

[11] ASTM C 494-05, "Standard Specification for Chemical Admixtures for Concrete", American Society for Testing and Material International, (2005).

[12] EFNARC, "Specifications and Guidelines for SelfCompacting Concrete", EFNARC, UK (www.efnarc.org) , pp. 1-32, (2005).

[13] B.S. Mahdi, Ph.D. thesis, Building and Construction Engineering, University of Technology, Iraq, (2009).
[14] H. Yazici , S. Aydın, H. Yiğiter, M. Y. Yardımc , G. Alptuna, journal of material in civil engineering ,22, No.11, pp.1093-1101,(2010).

[15] B.S 1881: Part 116, "Method for Determination of Compressive Strength of Concrete Cubes". , British Standards Institution, (1989).

[16] ASTM C496-04."Standard Test Method for Splitting Tensile Strength of Cylindrical Concrete Specimens", American Society for Testing and Materials, (2004).

[17] V. Ramakrishnan, V. Srinivasan, ACI Publications SP-79, pp. 797-812, (1984).

[18] M. Sonebi, L. Svermova. , P, J. M. Bartos, Materials' and Structures, pp.79-86, (2005).

[19] V.S. Parameswaran, T.S. Krishnamoorthy, K. Balasubramanian, , S. Gangadar, Structural Engineering Research Center, Taramani, Madras, India

[20] M.G. Krishman, , D. Elevaras, International Journal of Engineering research and technology, 3, Issue5, pp.534-537, (2014). 